\title{
Idade ao Primeiro Parto, Peso ao Parto e Desempenho Produtivo de Vacas Nelores e Cruzadas Charolês x Nelore ${ }^{1}$
}

\author{
Maurício Mello de Alencar ${ }^{2}$, José de Anchieta Leite Oliveira ${ }^{3}$, Manoel Araújo de Almeida ${ }^{4}$
}

\begin{abstract}
RESUMO - O objetivo deste trabalho foi comparar a idade ao primeiro parto (IPP) e o peso ao parto (PVP) de vacas da raça Nelore e cruzadas 1/4 Charolês + 3/4 Nelore (1CHA3NEL) e 5/8 Charolês + 3/8 Nelore (5CHA3NEL) e as relações peso do bezerro ao nascimento/ PVP (RPN) e peso do bezerro à desmama aos 270 dias/PVP (RPD) de bezerros nelores, 1CHA3NEL, 5CHA3NEL, canchins e 7/16 Charolês + 9/16 Nelore (7CHA9NEL). Análises de variância foram realizadas pelo método dos quadrados mínimos, usando-se modelos matemáticos que incluíram efeitos de ano e época de nascimento e grupo genético da vaca para IPP; ano, época e número do parto e grupo genético da vaca para PVP; e ano, época e número do parto, sexo e grupo genético do bezerro para RPN e RPD. O grupo genético influenciou as características estudadas. As médias estimadas de IPP e PVP foram iguais a 1073,0 \pm 9,0 dias e 425,4 $\pm 1,4 \mathrm{~kg}$ para as vacas nelores, 1043,5 $\pm 3,6$ dias e 447,4 $\pm 1,7 \mathrm{~kg}$ para as vacas $1 \mathrm{CHA} 3 \mathrm{NEL}$ e $966,1 \pm 5,2$ dias e 486,4 $\pm 2,7 \mathrm{~kg}$ para as vacas $5 \mathrm{CHA} 3 \mathrm{NEL}$, respectivamente. As médias

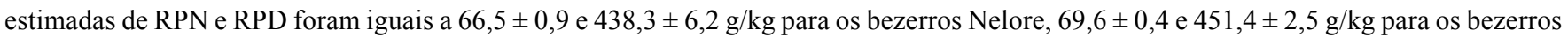
1CHA3NEL, 75,1 $\pm 0,5$ e 515,9 $\pm 3,3 \mathrm{~g} / \mathrm{kg}$ para os bezerros 5 CHA3NEL, 72,6 $\pm 0,7$ e 469,0 $\pm 4,9 \mathrm{~g} / \mathrm{kg}$ para os bezerros Canchim e 73,9 $\pm 0,8$ e 501,8 $\pm 5,8 \mathrm{~g} / \mathrm{kg}$ para os bezerros 7CHA9NEL, respectivamente. Os efeitos aditivo direto da raça Charolesa, como desvio da

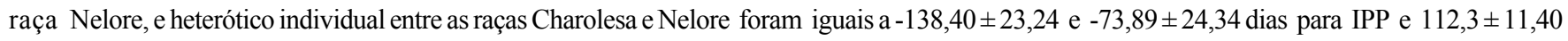
e $-12,23 \pm 9,08 \mathrm{~kg}$ para PVP, respectivamente. Os efeitos aditivos direto e materno e heteróticos individual e materno foram iguais a 0,6 $\pm 9,0 ;-11,1 \pm 4,9 ; 5,9 \pm 5,6 ;$ e 13,1 $\pm 3,9 \mathrm{~g} / \mathrm{kg}$ para RPN e 94,3 $\pm 66,4 ;-277,0 \pm 32,8 ;-19,0 \pm 39,9 ;$ e 206,4 $\pm 29,6 \mathrm{~g} / \mathrm{kg}$ para RPD, respectivamente. Os resultados indicam que, quanto maior a porcentagem de genes de Charolês na vaca, menor sua IPP, maior seu PVP e menores as RPN e RPD e, quanto maior a porcentagem esperada de heterozigose na vaca, menor sua IPP e maiores as relações RPN e RPD.
\end{abstract}

Palavras-chave: bovinos de corte, cruzamentos, eficiência produtiva, peso, vacas

\section{Age at First Calving, Calving Weight and Productive Performance of Straightbred Nellore and Crossbred Charolais $\mathbf{x}$ Nellore Cows}

\footnotetext{
ABSTRACT - The objective of this study was to compare age at first calving (AFC) and cow weight at calving (CWC) of straightbred Nellore and crossbred 1/4 Charolais + 3/4 Nellore (1CHA3NEL), and 5/8 Charolais + 3/8 Nellore (5CHA3NEL) cows, and birth weight of calf/CWC (BWR) and weaning weight of calf at 270 days/CWC (WWR) ratios of straightbred Nellore and crossbred 1CHA3NEL, 5CHA3NEL, Canchim (5/8 Charolais + 3/8 Nellore) and 7/16 Charolais + 9/16 Nellore (7CHA9NEL) calves. Analyses of variance were carried out by the least squares method, with models that included the effects of year and season of birth, and genetic group of cow for AFC; year, season, and age of cow at calving, and genetic group of cow for CWC; and year, season, and age of cow at calving, and sex and genetic group of calf for BWR and WWR. Genetic group affected all studied traits. The least squares means for AFC and CWC were $1073.0 \pm 9.0$ days and $425.4 \pm 1.4 \mathrm{~kg}$ for the Nellore, $1043.5 \pm 3.6$ days and $447.4 \pm 1.7 \mathrm{~kg}$ for the $1 \mathrm{CHA} 3 \mathrm{NEL}$, and $966.1 \pm 5.2$ days and $486.4 \pm 2.7 \mathrm{~kg}$ for the $5 \mathrm{CHA} 3 \mathrm{NEL}$ cows, respectively. The least squares means for BWR and WWR were $66.5 \pm 0.9$ and $438.3 \pm$ $6.2 \mathrm{~g} / \mathrm{kg}$ for the Nellore, $69.6 \pm 0.4$ and $415.4 \pm 2.5 \mathrm{~g} / \mathrm{kg}$ for the $1 \mathrm{CHA} 3 \mathrm{NEL}, 75.1 \pm 0.5$ and $515.9 \pm 3.3 \mathrm{~g} / \mathrm{kg}$ for the $5 \mathrm{CHA} 3 \mathrm{NEL}$, $72.6 \pm 0.7$ and $469.0 \pm 4.9 \mathrm{~g} / \mathrm{kg}$ for the Canchim, and $73.9 \pm 0.8$ and $501.8 \pm 5.8 \mathrm{~g} / \mathrm{kg}$ for the $7 \mathrm{CHA}$ NEL calves, respectively. The additive direct effect of the Charolais, as a deviation of the Nellore, and the heterotic individual effect of the Charolais and Nellore breeds were $-138.40 \pm 23.24$ and $-73.89 \pm 24.34$ days for AFC, and $112.30 \pm 11.40$ and $-12.23 \pm 9.08 \mathrm{~kg}$ for CWC, respectively. The additive direct, additive maternal, heterotic individual and heterotic maternal effects were $0.6 \pm 9.0,-11.1 \pm 4.9,5.9 \pm 5.6$, and $13.1 \pm 3.9 \mathrm{~g} / \mathrm{kg}$ for $\mathrm{BWR}$ and $94.3 \pm 66.4,-277.0 \pm 32.8,-19.0 \pm 39.9$, and $206.4 \pm 29.6 \mathrm{~g} / \mathrm{kg}$ for WWR, respectively. The results show that as higher was the percentage of cows Charolais genes, the smaller its AFC, the higher its CWC, and the smaller the BWR and WWR ratios; and the as higher the expected heterozygosity in the cow, the smaller its AFC, and the higher the BWR and WWR.

Key Words: beef cattle, crossbreeding, productive efficiency, cows

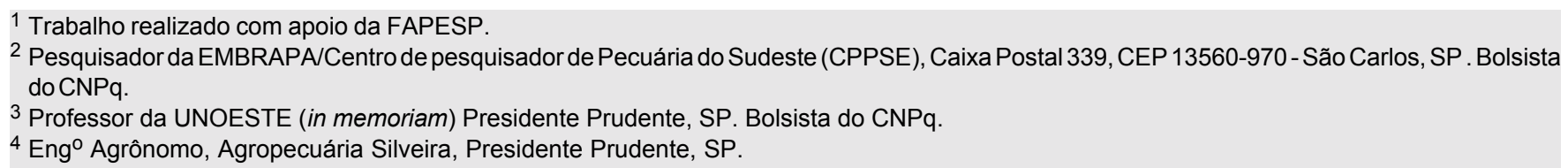




\section{Introdução}

O cruzamento entre raças bovinas pode contribuir para o aumento da produtividade da bovinocultura de corte do País. ALENCAR (1997), revisando trabalhos de cruzamento entre raças bovinas de corte no Brasil, observou superioridade dos animais cruzados em relação aos zebus puros, para características reprodutivas, de habilidade materna e de crescimento. $O$ peso da vaca também tem sido estudado no Brasil (ALENCAR, 1988; EUCLIDES FILHO et al., 1992; OLIVEIRA et al., 1995; e ALENCAR et al., 1997), uma vez que as vacas mais pesadas e que produzem mais leite consomem mais alimentos (McMORRIS e WILTON, 1986) e podem não ser as mais eficientes (EUCLIDES FILHO et al., 1992). ALENCAR et al. (1998) e TREMATORE et al. (1998) estudaram os pesos ao nascimento e à desmama e estimaram efeitos aditivos e heteróticos para essas características, em animais da raça Nelore e cruzados Charolês x Nelore. O objetivo deste trabalho é estudar a idade ao primeiro parto, o peso da vaca ao parto e as relações de peso do bezerro/peso da vaca ao parto dos animais utilizados por esses autores nos respectivos trabalhos.

\section{Material e Métodos}

Foram utilizadas observações de idade ao primeiro parto (IPP), peso das vacas ao parto (PVP) e pesos dos bezerros ao nascimento $(\mathrm{PBN})$ e à desmama (PBD) de um rebanho comercial situado na região oeste do Estado de São Paulo. As vacas, nesse rebanho, permaneceram com seus bezerros em pastagens dos capins coast-cross (Cynodon dactylum Stent), colonião (Panicum maximum Jacq) e pangola (Digitaria decumbens Stent), recebendo suplemento mineral comercial à vontade. O período de acasalamentos estendia-se de maio a fevereiro.

Para o estudo de IPP foram utilizadas as observações de 170, 898 e 609 fêmeas Nelore, 1/4 Charolês $+3 / 4$ Nelore (filhas de touros $F_{1}$ Charolês - Nelore e vacas Nelore) e 5/8 Charolês $+3 / 8$ Nelore (inclui Canchim; filhas de touros Charolês e vacas $1 / 4$ Charolês $+3 / 4$ Nelore ou de touros e vacas 5/8 Charolês $+3 / 8$ Nelore), respectivamente. Para o estudo de PVP foram utilizadas 1506, 1435 e 448 observações de fêmeas dos mesmos grupos genéticos, respectivamente. Para o estudo das relações PBN/PVP (RPN) e PBD/PVP (RPD), foram utilizadas 193 e 187 observações de animais Nelore, 1311 e 1250 observações de animais 1/4 Charolês $+3 / 4$ Nelore (filhos de touros $\mathrm{F}_{1}$ Charolês - Nelore e vacas Nelore), 310 e 216 observações de animais 7/16 Charolês + 9/16 Nelore (filhos de touros $5 / 8$ Charolês $+3 / 8$ Nelore e vacas $1 / 4$ Charolês $+3 / 4$ Nelore), 1110 e 937 observações de animais $5 / 8$ Charolês $+3 / 8$ Nelore (filhos de touros Charoleses e vacas $1 / 4$ Charolês $+3 / 4$ Nelore) e 446 e 419 observações de animais Canchim (filhos de touros e vacas 5/8 Charolês $+3 / 8$ Nelore).

As observações de IPP foram analisadas utilizando-se modelo matemático que incluiu os efeitos de ano (1980 a 1988) e época ( $1=$ janeiro a março; $2=$ abril a junho; 3 = julho a setembro; e $4=$ outubro a dezembro) de nascimento e grupo genético da vaca. As observações de PVP foram analisadas utilizandose modelo matemático que incluiu os efeitos de ano (1983 a 1989) e época (1 a 4) do parto, número do parto (1 a 6) e grupo genético da vaca. O modelo matemático para a análise de RPN e RPD incluiu os efeitos de ano (1983 a 1989), época (1 a 4) e número do parto (1 a 6), sexo e grupo genético do bezerro. Antes de calcular os RPDs, os pesos à desmama foram ajustados para 270 dias de idade. As análises foram feitas por intermédio do método dos quadrados mínimos, utilizando-se o procedimento GLM (SAS, 1990).

\section{Resultados e Discussão}

O resumo das análises de variância das características estudadas é apresentado na Tabela 1. Observa-se que todos os efeitos incluídos nos modelos influenciaram significativamente $(\mathrm{P}<0,01$ ou $\mathrm{P}<0,05)$ as características estudadas. Não se observou tendência lógica nas mudanças de IPP com o passar dos anos. Entretanto, PVP aumentou no período de 1983 (441 kg) a $1987(476 \mathrm{~kg})$ e diminuiu novamente até 1989 (446 kg). Houve tendência de redução de RPN e RPD no período de $1983(74,7$ e 493,6 g/kg) até $1988(70,1$ e $459,8 \mathrm{~g} / \mathrm{kg})$, havendo novo aumento em $1989(73,5$ e 468,3 g/kg). Estas mudanças nas relações de pesos refletem as mudanças no PVP e também nos pesos ao nascimento e à desmama, conforme observado por ALENCAR et al. (1998).

As médias estimadas de IPP e PVP de acordo com a época de nascimento ou do parto encontramse na Tabela 2 e as de RPN e RPD, na Tabela 3. Verifica-se que vacas mais jovens ao primeiro parto foram as nascidas durante o segundo semestre, o que parece lógico, pois a maior parte das concepções ocorre na época das águas, quando as novilhas nasci- 
Rev. bras. zootec.

Tabela 1 - Resumo das análises de variância de idade ao primeiro parto (IPP), peso ao parto (PVP) e relações de peso ao nascimento (RPN) e à desmama (RPD)

Table 1 - Summary of the analyses of variance for age at first calving (AFC), cow weight at calving (CWC), and weight ratios at birth (BWR) and weaning (WWR)

\begin{tabular}{|c|c|c|c|c|c|}
\hline \multirow{3}{*}{$\begin{array}{l}\text { Fonte de variação } \\
\text { Source of variation }\end{array}$} & \multirow{3}{*}{$\begin{array}{l}g l^{2} \\
d f^{2}\end{array}$} & \multicolumn{4}{|c|}{$\begin{array}{l}\text { Quadrados médios } \\
\text { Mean squares }^{3}\end{array}$} \\
\hline & & IPP & PVP & RPN & RPD \\
\hline & & $A F C$ & $C W C$ & $B W R$ & $W W R$ \\
\hline $\begin{array}{l}\text { Ano de nasc. } \\
\text { Year of birth }\end{array}$ & $8 / 6 / 6 / 6$ & $58759 * *$ & $123331 * *$ & $2,8 * *$ & $39,2 * *$ \\
\hline $\begin{array}{l}\text { Época de nasc. }{ }^{1} \\
\text { Season of birth }\end{array}$ & $3 / 3 / 3 / 3$ & $219389 * *$ & $267787 * *$ & $4,8^{* *}$ & $829,7 * *$ \\
\hline $\begin{array}{l}\text { Número do parto } \\
\text { Calving number }\end{array}$ & $-/ 5 / 5 / 5$ & - & $185908 * *$ & $1,1 * *$ & $13,2 *$ \\
\hline $\begin{array}{l}\text { Sexo do bezerro } \\
\text { Sex of calf }\end{array}$ & $-/-/ 1 / 1$ & - & - & $11,8 * *$ & $1370,2 * *$ \\
\hline $\begin{array}{l}\text { Grupo genético } \\
\text { Genetic group }\end{array}$ & $2 / 2 / 4 / 4$ & $877270 * *$ & $347409 * *$ & $3,2 * *$ & $398,7^{* *}$ \\
\hline $\begin{array}{l}\text { Resíduo } \\
\text { Error }\end{array}$ & $1662 / 3372 / 3350 / 2989$ & 8947 & 1945 & 0,1 & 5,7 \\
\hline $\mathrm{R}^{2}(\%)$ & & 20,7 & 32,0 & 14,0 & 27,3 \\
\hline
\end{tabular}

$* * \mathrm{P}<0,01$.

1 Ano e época do parto para PVP, RPN e RPD.

2 Graus de liberdade de IPP/PVP/RPN/RPD.

3 x 1000 para RPN e RPD.

1 Year and season of calving for CWC, BWR and WWR.

2 Degrees offreedomforAFC/CWC/BWR/WWR.

$3 \times 1000$ for $B W R$ and WWR.

Tabela 2 - Médias ( \pm erros-padrão) estimadas da idade ao primeiro parto (IPP, dias) e do peso da vaca ao parto (PVP, kg), de acordo com a época do parto

Table 2 - Least squares means ( \pm standard errors) for age at first calving (AFC, days) and cow weight at calving (CWC, kg), according to season of birth

\begin{tabular}{|c|c|c|c|c|}
\hline \multirow[b]{2}{*}{ Época } & \multicolumn{2}{|c|}{$\begin{array}{l}\text { IPP } \\
A F C\end{array}$} & \multicolumn{2}{|c|}{$\begin{array}{l}\text { PVP } \\
C W C\end{array}$} \\
\hline & $\mathrm{N}^{1}$ & Média & $\mathrm{N}^{1}$ & Média \\
\hline Season & $N^{1}$ & Mean & $N^{I}$ & Mean \\
\hline Jan. - Mar. & 364 & $1060,6 \pm 5,8$ & 516 & $464,9 \pm 2,3$ \\
\hline $\begin{array}{l}\text { Jan. - Mar. } \\
\text { Abr. - Jun. } \\
\text { Apr. - Jun. }\end{array}$ & 372 & $1040,3 \pm 5,9$ & 581 & $475,5 \pm 2,1$ \\
\hline $\begin{array}{l}\text { Jul. - Set. } \\
\text { Jul. - Sep. }\end{array}$ & 727 & $1017,5 \pm 4,1$ & 1469 & $436,7 \pm 1,4$ \\
\hline $\begin{array}{l}\text { Out. - Dez } \\
\text { Oct. - Dec. }\end{array}$ & 214 & $992,0 \pm 7,0$ & 823 & $435,1 \pm 1,7$ \\
\hline
\end{tabular}

${ }_{1}^{1}$ Número de observações.

${ }^{1}$ Number of observations.

das no segundo semestre são mais jovens. As vacas mais pesadas ao parto foram as paridas de janeiro a julho, o que também é lógico, pois passaram o final da gestação em pastos com boa disponibilidade de forragens. RPN e RPD foram maiores para os nascimentos ocorridos no segundo semestre, sendo que, dentro deste, RPN foi maior para o último trimestre, enquanto RPD foi maior para os nascimentos ocorridos no período de julho a setembro, época em que os bezerros foram mais pesados ao nascimento e à desmama (ALENCAR et al., 1998).

O PVP aumentou linearmente do primeiro $(416 \mathrm{~kg})$ ao sexto $(469 \mathrm{~kg})$ parto. Houve tendência de redução linear de RPN e RPD com o aumento do número de partos da vaca, do primeiro $(73,9 \mathrm{e} 482,5 \mathrm{~g} / \mathrm{kg})$ ao sexto $(69,3$ e 467,3 g/ $/ \mathrm{kg})$ partos. O aumento nos pesos do bezerro com o aumento da idade da vaca, observado por ALENCAR et al. (1998), não foi suficiente para contrabalançar o aumento no peso da vaca ao parto, fazendo com que as relações de peso reduzissem com o envelhecimento da vaca.

Os bezerros machos apresentaram RPN $(73,4 \pm 0,4$ vs. $69,7 \pm 0,4 \mathrm{~g} / \mathrm{kg})$ e RPD $(496,5 \pm 2,7 \mathrm{vs}$. $453,7 \pm 2,6 \mathrm{~g} / \mathrm{kg}$ ) maiores que as fêmeas, como resultado de seus maiores pesos (ALENCAR et al., 1998). 
Tabela 3 - Médias ( \pm erros-padrão) estimadas das relações de pesos ao nascimento (RPN, g/kg) e à desmama (RPD, g/kg), de acordo com a época do parto

Table 3 - $\quad$ Least squares means ( \pm standard errors) for weight ratios at birth (BWR, g/kg) and weaning (WWR, g/kg) according to season of birth

\begin{tabular}{|c|c|c|c|c|}
\hline \multirow[b]{2}{*}{ Época } & \multicolumn{2}{|c|}{$\begin{array}{l}\text { RPN } \\
B W R\end{array}$} & \multicolumn{2}{|c|}{$\begin{array}{l}\text { RPD } \\
W W R\end{array}$} \\
\hline & $\mathrm{n}^{1}$ & Média & $\mathrm{N}^{1}$ & Média \\
\hline Season & & Mean & $N^{1}$ & Mean \\
\hline Jan. - Mar. & 508 & $69,7 \pm 0,6$ & 433 & $441,2 \pm 4,3$ \\
\hline $\begin{array}{l}\text { Jan. - Mar. } \\
\text { Abr. - Jun. } \\
\text { Apr. - Jun. }\end{array}$ & 579 & $68,8 \pm 0,5$ & 517 & $456,1 \pm 3,8$ \\
\hline $\begin{array}{l}\text { Jul. - Set. } \\
\text { Jul. - Sep. }\end{array}$ & 1462 & $72,9 \pm 0,4$ & 1344 & $519,3 \pm 2,6$ \\
\hline $\begin{array}{l}\text { Out. - Dez } \\
\text { Oct. - Dec. }\end{array}$ & 821 & $74,9 \pm 0,5$ & 715 & $483,8 \pm 3,2$ \\
\hline
\end{tabular}

Os resultados obtidos neste estudo para IPP, PVP, RPN e RPD concordam com os obtidos por ALENCAR e BUGNER (1987 e 1989), nas raças Nelore e Canchim; PÁDUA et al. (1994) e OLIVEIRA et al. (1995), na raça Nelore; e ALENCAR et al. (1997), para vacas da raça Nelore e cruzadas Charolês-Nelore, Limousin-Nelore e Tabapuã-Gir.

As médias estimadas de IPP e PVP de acordo com o grupo genético da vaca são apresentadas na Tabela 4 . Observa-se que as vacas mais jovens ao primeiro parto foram as 5/8 Charolês (966,1 $\pm 5,2$ dias), seguidas das 1/4 Charolês (1043,5 $\pm 3,6$ dias). As vacas Nelore foram as mais tardias $(1073,0 \pm 9,0$ dias $)$. As vacas mais pesadas ao parto foram as $5 / 8$ Charolês $(486,4 \pm 2,7 \mathrm{~kg})$, seguidas das $1 / 4$ Charolês $(447,4 \pm 1,7 \mathrm{~kg}$ ) e das Nelore $(425,4 \pm 1,4 \mathrm{~kg})$. Estes resultados são coerentes considerando-se o "grau de sangue" de Charolês e a heterozigosidade $(0,0 \%$ para as Nelore, $50,0 \%$ para as $1 / 4$ e $75,0 \%$ para as $5 / 8$ ) esperada nos animais.

As médias estimadas de RPN e RPD de acordo com o grupo genético do bezerro são apresentadas na Tabela 5. Observa-se que as maiores relações são as dos bezerros $5 / 8$ Charolês $+3 / 8$ Nelore e 7/16 Charolês + 9/16 Nelore, que possuem as melhores combinações de proporções de genes de Charolês no bezerro $(5 / 8$ e $7 / 16)$ e na vaca $(3 / 4)$ e de percentuais de heterozigoses individuais $(75,00 \% \mathrm{e}$ $56,25 \%)$ e maternas $(50,00 \%)$, o que lhes confere maiores pesos ao nascimento e à desmama (ALENCAR et al., 1998; TREMATORE et al., 1998), além de serem filhos de vacas com peso ao parto intermediário (Tabela 4). Os bezerros Nelore, apesar de serem filhos das vacas mais leves ao parto (Tabela 4), foram os que apresentaram RPN e RPD menores, provavelmente em razão dos menores pe- sos ao nascimento e à desmama, resultado da ausência de genes do Charolês e de vigor híbrido (ALENCAR et al., 1998; TREMATORE et al., 1998). Os bezerros 1/4 Charolês e Canchim apresentaram RPNs e RPDs intermediários pelos mesmos motivos já citados.

Outros autores, no Brasil, também verificaram efeitos significativos de grupo genético da vaca sobre as características estudadas neste trabalho. ALENCAR e BUGNER (1987) verificaram menor idade ao primeiro parto para fêmeas da raça Canchim (5/8 Charolês $+3 / 8$ Nelore) em comparação às fêmeas da raça Nelore. ALENCAR e BUGNER (1987 e 1989) observaram maior peso ao parto para vacas da raça Canchim em comparação às da raça Nelore. ALENCAR et al. (1997) verificaram maior peso ao parto para vacas $1 / 2$ Charolês $+1 / 2$ Nelore e $1 / 2$ Limousin $+1 / 2$ Nelore em relação a vacas 1/4 Charolês $+3 / 4$ Nelore e 1/4 Limousin + 3/4 Nelore, respectivamente. EUCLIDES FILHO et al. (1992) observaram efeito significativo do grupo genético da vaca sobre sua eficiência produtiva, medida em termos de peso de bezerro à desmama/peso metabólico da vaca à desmama do bezerro, sendo que as vacas $1 / 2$ Fleckvieh $+1 / 2$ Nelore foram mais eficientes que as $1 / 2$ Chianina $+1 / 2$ Nelore. ALENCAR (1988), entretanto, não observou diferença entre as RPDs de vacas das raças Canchim e Nelore, quando acasaladas com touros das respectivas raças. ALENCAR et al. (1997) observaram que vacas $1 / 2$ Limousin $+1 / 2$ Nelore, apesar de produzirem bezerros mais pesados à desmama do que vacas $1 / 4$ Limousin $+3 / 4$ Nelore, quando acasaladas com touros Nelore, produziram RPDs significativamente menores. Para as vacas cruzadas Charolês x Nelore observou-se a mesma tendência. 
Rev. bras. zootec.

Tabela 4 - Médias ( \pm erros-padrão) estimadas da idade ao primeiro parto (IPP, dias) e do peso da vaca ao parto (PVP, kg), de acordo com o grupo genético da vaca

Table 4 - Least squares means ( \pm standard errors) for age at first calving (AFC, days) and cow weight at calving (CWC, kg) according to the genetic group of the cow

\begin{tabular}{|c|c|c|c|c|}
\hline \multirow{3}{*}{$\begin{array}{l}\text { Grupo genético } \\
\text { Genetic group }\end{array}$} & \multicolumn{2}{|c|}{$\begin{array}{l}\text { IPP } \\
A F C\end{array}$} & \multicolumn{2}{|c|}{$\begin{array}{l}\text { PVP } \\
C W C\end{array}$} \\
\hline & $\mathrm{N}^{1}$ & Média & $\mathrm{N}^{1}$ & Média \\
\hline & $N^{1}$ & Mean & $N^{l}$ & Mean \\
\hline Nelore & 170 & $1073,0 \pm 9,0$ & 1506 & $425,4 \pm 1,4$ \\
\hline $\begin{array}{l}\text { Nellore } \\
1 / 4 \text { Charolês }+3 / 4 \text { Nelore } \\
\text { 1/4 Charolais }+3 / 4 \text { Nellore }\end{array}$ & 898 & $1043,5 \pm 3,6$ & 1435 & $447,4 \pm 1,7$ \\
\hline $\begin{array}{l}5 / 8 \text { Charolês }+3 / 8 \text { Nelore } \\
5 / 8 \text { Charolais }+3 / 8 \text { Nellore } \\
\text { Geral }\end{array}$ & 609 & $966,1 \pm 5,2$ & 448 & $486,4 \pm 2,7$ \\
\hline Overall & 1677 & $1027,5 \pm 2,3$ & 3389 & $453,1 \pm 0,7$ \\
\hline
\end{tabular}

${ }_{1}^{1}$ Número de observações.

1 Number of observations.

Para auxiliar na interpretação dos resultados, mesmo com o pequeno número de grupos genéticos, o efeito aditivo direto da raça Charolesa, como desvio da raça Nelore, e o efeito heterótico individual entre as raças Charolesa e Nelore para IPP e PVP foram estimados utilizando-se a metodologia da regressão parcial proposta por KOGER et al. (1975), ou seja, substituindo-se o grupo genético da vaca nos modelos matemáticos pelas covariáveis porcentagem de Charolês e porcentagem de heterozigose esperada na vaca, respectivamente. Neste caso, foram consideradas as fêmeas Nelore, 1/4 Charolês $+3 / 4$ Nelore, 5/8 Charolês $+3 / 8$ Nelore e Canchim. Considerou-se também que os efeitos maternos e paternos (aditivos e heteróticos) são inexistentes para estas características. As covariáveis incluídas no modelo influenciaram IPP $(\mathrm{P}<0,01)$, mostrando a importância dos efeitos aditivo e heterótico para esta característica. $\mathrm{O}$ efeito aditivo direto da raça Charolesa, como desvio da raça Nelore, foi igual a $-138,40 \pm 23,24$ dias, indicando que, nas condições deste trabalho, quanto maior a porcentagem de genes de Charolês na novilha, menor é a sua idade ao primeiro parto. $\mathrm{O}$ efeito heterótico individual foi igual a $-73,89 \pm 24,34$ dias, indicando que quanto maior a heterozigose na novilha, menor é a sua idade ao primeiro parto. Para PVP apenas o efeito aditivo direto $(112,26 \pm 11,40 \mathrm{~kg})$ foi significativo $(\mathrm{P}<0,01)$, mostrando que, quanto maior a porcentagem de Charolês na fêmea, maior seu peso ao parto. O efeito heterótico individual $(-12,23 \pm 9,08$ $\mathrm{kg})$ não foi significativo $(\mathrm{P}>0,17)$, indicando que a porcentagem esperada de locos em heterozigose na vaca não influenciou o seu peso ao parto.

Estimaram-se os efeitos aditivos direto e materno e heteróticos individual e materno para RPN e RPD, considerando-as como características dos bezerros, apesar de serem função também de PVP. Neste caso o grupo genético do bezerro foi substituído no modelo matemático pelas covariáveis proporções de genes do Charolês no bezerro e na vaca e de heterozigose esperada no bezerro e na vaca. Os efeitos aditivos direto e materno e heteróticos individual e materno obtidos foram iguais a $0,6 \pm 9,0(\mathrm{P}>0,94) ;-11,1 \pm 4,9$ $(\mathrm{P}<0,03) ; 5,9 \pm 5,6(\mathrm{P}>0,20) ; \mathrm{e} \mathrm{13,1 \pm 3,9}(\mathrm{P}<0,001)$ $\mathrm{g} / \mathrm{kg}$ para $\mathrm{RPN}$ e $94,3 \pm 66,4(\mathrm{P}>0,15) ;-277,0 \pm 32,8$ $(\mathrm{P}<0,001) ;-19,0 \pm 39,9(\mathrm{P}>0,60) ;$ e $206,4 \pm 29,6$ $(\mathrm{P}<0,001) \mathrm{g} / \mathrm{kg}$ para RPD. Estes resultados indicam que, quanto maior a proporção de Charolês na vaca, menores as relações de pesos ao nascimento e à desmama, e quanto maior a heterozigose na vaca, maiores as relações de pesos ao nascimento e à desmama. Em outras palavras, uma vaca com 100\% de genes do Charolês produz menos 248 gramas de bezerro à desmama por quilograma de vaca ao parto, em relação a uma vaca $100 \%$ Nelore, independentemente do grupo genético do bezerro; e uma vaca com $100 \%$ de heterozigose, ou seja, $1 / 2$ Charolês $+1 / 2$ Nelore filha de pais puros, produzirá mais $185 \mathrm{~g}$ de bezerro à desmama por quilograma de vaca ao parto, em relação a uma vaca com $0 \%$ de heterozigose, ou seja, uma vaca pura, independentemente do seu bezerro. Verificando-se os valores dos efeitos aditivos (diretos e maternos) e heteróticos (individuais e maternos) obtidos por TREMATORE et al. (1998) para os pesos ao nascimento $(2,07 ; 6,77 ; 1,66$; e $0,62 \mathrm{~kg})$ e à desmama $(9,99 ;-23,31 ; 14,77 ; \mathrm{e} 44,16 \mathrm{~kg})$, para $\mathrm{o}$ mesmo rebanho deste estudo, e os valores dos efeitos aditivo direto $(112,26 \mathrm{~kg})$ e heterótico individual $(-12,23 \mathrm{~kg})$ obtidos para PVP, observa-se coerência nas estimativas obtidas para RPN e RPD. 
Tabela 5 - Médias ( \pm erro padrão) estimadas das relações de peso ao nascimento (RPN, g/kg) e à desmama (RPD, g/kg), de acordo com o grupo genético do bezerro

Table 5 - $\quad$ Least squares means ( \pm standard errors) for weight ratios at birth (BWR, g/kg) and weaning (WWR, g/kg) according to genetic group of calf

\begin{tabular}{|c|c|c|c|c|}
\hline \multirow{3}{*}{$\begin{array}{l}\text { Grupo genético } \\
\text { Genetic group }\end{array}$} & \multicolumn{2}{|c|}{$\begin{array}{l}\mathrm{RPN} \\
B W R\end{array}$} & \multicolumn{2}{|c|}{$\begin{array}{l}\text { RPD } \\
W W R\end{array}$} \\
\hline & $\mathrm{N}^{1}$ & Média & $\mathrm{N}^{1}$ & Média \\
\hline & & Mean & $N^{1}$ & Mean \\
\hline Nelore & 193 & $66,5 \pm 0,9$ & 187 & $438,3 \pm 6,2$ \\
\hline Nellore & & & & \\
\hline $\begin{array}{l}\text { 7/16 Charolês }+9 / 16 \text { Nelore } \\
\text { 7/16 Charolais }+9 / 16 \text { Nellore }\end{array}$ & 310 & $73,9 \pm 0,8$ & 216 & $501,8 \pm 5,8$ \\
\hline $\begin{array}{l}\text { Canchim } \\
\text { Canchim }\end{array}$ & 446 & $72,6 \pm 0,7$ & 419 & $469,0 \pm 4,9$ \\
\hline $\begin{array}{l}\text { 1/4 Charolês }+3 / 4 \text { Nelore } \\
1 / 4 \text { Charolais }+3 / 4 \text { Nellore }\end{array}$ & 1311 & $69,6 \pm 0,4$ & 1250 & $451,4 \pm 2,5$ \\
\hline $\begin{array}{l}5 / 8 \text { Charolês }+3 / 8 \text { Nelore } \\
5 / 8 \text { Charolais }+3 / 8 \text { Nellore }\end{array}$ & 1110 & $75,1 \pm 0,5$ & 937 & $515,9 \pm 3,3$ \\
\hline $\begin{array}{l}\text { Geral } \\
\text { Overall }\end{array}$ & 3370 & $71,5 \pm 0,2$ & 3009 & $475,1 \pm 1,4$ \\
\hline
\end{tabular}

\section{Conclusões}

Nas condições deste estudo, pode-se concluir que, quanto maior a porcentagem de genes de Charolês na vaca, menor sua idade ao primeiro parto, maior seu peso ao parto e menores as relações de pesos ao nascimento e à desmama, e quanto maior a porcentagem esperada de heterozigose na vaca, menor sua idade ao primeiro parto e maiores as relações de pesos ao nascimento e à desmama.

\section{Referências Bibliográficas}

ALENCAR, M.M. 1988. Desempenho produtivo de fêmeas das raças Canchim e Nelore. V. Desenvolvimento dos bezerros. R. Soc. Bras. Zootec., 17(5):411-420.

ALENCAR, M.M. Los cruzamientos para la producción de carne bovina. In: CONGRESO INTERNACIONAL DE TRANSFERENCIA DE TECNOLÓGICA AGROPECUARIA, 5, 1997, Asunción. Anais... Asunción: CEA, 1997, p.111-122.

ALENCAR, M.M., BUGNER, M. 1987. Desempenho produtivo de fêmeas das raças Canchim e Nelore. V. Primeiro parto. Pesq. Agropec. Bras., 22(8):867-872.

ALENCAR, M.M., BUGNER, M. 1989. Desempenho produtivo de fêmeas das raças Canchim e Nelore. IV. Segundo parto. Pesq. Agropec. Bras., 24(10):1217-1220.

ALENCAR, M.M., TREMATORE, R.L., OLIVEIRA, J.A.L. et al. 1998. Características de crescimento até a desmama de bovinos da raça Nelore e cruzados Charolês x Nelore. R. Bras. Zootec., 27(1):40-46.

ALENCAR, M.M., TREMATORE, R.L., OLIVEIRA, J.A .L. et al. 1997. Desempenho produtivo de vacas da raça Nelore e cruzadas Charolês x Nelore, Limousin x Nelore e Tabapuã x Gir. R. Bras. Zootec., 26(3):467-472.

EUCLIDES FILHO, K., FIGUEIREDO, G.R., THIAGO,
L.R.L.S. Eficiência biológica de produção de carne de diferentes grupos genéticos. In: REUNIÃO ANUAL DA SOCIEDADE BRASILEIRA DE ZOOTECNIA, 29, 1992, Lavras. Anais... Lavras: SBZ, 1992, p.124.

KOGER,.M., PEACOCK, F.M., CROCKETT, J.R. 1975. Heterosis effects on weaning performance of BrahmanShorthorn calves. J. Anim. Sci., 40(4):826-833.

McMORRIS, M.R., WILTON, J.W. 1986. Breeding system, cow weight and milk yield effects on various biological variables in beef production. J. Anim. Sci., 63(5):1361-1372.

OLIVEIRA, J.A.L., ALENCAR, M.M., LIMA, R. 1995. Eficiência produtiva de vacas da raça Nelore. R. Soc. Bras. Zootec., 24(3):445-452.

PÁDUA, J.T., MUNARI, D.P., WATANABE, Y.F. et al. 1994. Avaliação de efeitos de ambiente e da repetibilidade de características reprodutivas em bovinos da raça Nelore. $R$. Soc. Bras. Zootec., 23(1):126-132.

SAS statistical analysis systems user's guide: Stat, Version 6.4. ed. Cary: SAS Institute, 1996, v.2.

TREMATORE, R.L., ALENCAR, M.M., BARBOSA, P.F. et al. 1998. Estimativas de efeitos aditivos e heteróticos para características de crescimento pré-desmama em bovinos Charolês - Nelore. R. Bras. Zootec., 27(1):87-94.
Recebido em: 09/02/98

Aceito em: 16/12/98 